\title{
Providing the Developmental Model of a Comprehensive System of Prioritizing Occupational Risks Using Analytical Hierarchy Process (AHP) Technique in the Management of Integrated Health, Safety and Environment (Case Study of Oil Industrial Contractors)
}

\author{
Homa Pouresfandyani ${ }^{1} \&$ Sara Najiazarpour ${ }^{1}$ \\ ${ }^{1}$ Master of Industrial Engineering (MA), Department of industrial engineering, Iran University of Science \& \\ Technology, Tehran, Iran \\ Correspondence: Homa Pouresfandyani, Master of Industrial Engineering (MA), Department of industrial \\ engineering, Iran University of Science \& Technology, Tehran, Iran. E-mail: h.pouresfandyani@gmail.com
}

Received: August 28, 2019

Accepted: September 24, 2018

Online Published: May 30, 2019

doi:10.5539/mas.v13n6p149

URL: https://doi.org/10.5539/mas.v13n6p149

\begin{abstract}
In this study, researchers designed a functional decision supporting model for workplaces for managers and showed its application by implementing it in health, safety and environment fields.

Researchers used Excel software to demonstrate the ease of use of this method. This model is designed to help managers for decision-making to select and allocate resources to optimize risk of irreversible and unacceptable risks. In this regard, detailed quantitative risk assessment methods and techniques AHP expert's extraction, classification and has been structured; to help managing workplaces risks and reducing the effects other than representing the applications of multi-criteria decision making techniques especially Analytical Hierarchy Process (AHP) technique, and in the end, to attribute resources in the best possible way. This model comes as a decision support system and is used to ease, the accuracy of decisions and reassuring them.

This study suggests the use of multi-criteria decision-making techniques in large-scale projects and organizational risk management process for managers and reassuring them in terms of efficiency and effectiveness of steps taken to reduce and control occupational risks in the workplace and promise reduction irreparable effects for both organizations and for society, and to optimize the allocation of limited resources of organization. To carry out all stages of computational and analytic hierarchy process technique, Excel software was used in this study to show that this technique with capacity is also applicable in various companies.
\end{abstract}

Keywords: risk management, decision support system, analytical hierarchy process and multi-criteria decision-making models

\section{Introduction}

Given the complexities of today's world, globalization, global village, increased competition and changes have been made in recent centuries, the West has led to the development that over a period of time, attention has been directed toward sustainable development

East, as well as Iran, due to desire and need to have interaction with the West is obliged to follow them and discussions (database of government). Enjoying environment, is a concept that is necessary to do composers and law enforcement development activities compatible with the environment (Magiran, 2013).

Decision making is considered as an integral component of management and is apparent in every management task; to determine the organization's policies, the formulation of objectives, organization design, selection, evaluation and management decision-making in all major components and basic elements. Although to address the target, it is necessary that the manager determines the policy and draws general policies, the way the organization can go ascertained;

Decision-making, forms the foundation of management duties; because if goal setting, policies, determination of strategies, laws and regulations, ways of working, the selection and recruitment of human resources, assign tasks and responsibilities of staff and the administration, control and evaluation of their performance are considered 
the duties of the director; decision-making is a prerequisite of all these measures (Modiriyat_omumi_alvani.pdf).

Some experts believe that the quality of management is subordinate to the quality of decision-making and that the decision making alone is the most important duty of the manager;

Managers usually define making decision as their primary task; Beacuse for them it is obvious that the goals of the organization should be sought which way to choose, what to do, who's in charge and responsible for what, and how, where and when works are done (Decision making process in organization (written by esfandiar saadat)- library of mehr excellent training center).

Given the shortcomings in the application of multi-criteria decision-making methods and techniques and offered job in prioritizing risks regarding this integration and systematic technique in prioritizing occupational risks and lack of management decision support in healthcare, safety and the environment, this study sought to develop a comprehensive system for prioritizing occupational risks after risk assessment by professionals in the fields of health, safety and environment in order to ensure the integrity and effectiveness of the decisions.

We used the AHP to determine the relative importance of the criteria and the options available in risk assessment, data analysis and ultimately prioritize job related risks.

Checklist frameworks and questionnaires are based on the list of paired comparisons matrices defined in hierarchical structure technique.

We used the AHP to determine the relative importance of the criteria and the options available in risk assessment, data analysis and ultimately prioritize risks related Job. Checklist frameworks and questionnaires based on the list of paired comparisons matrices hierarchical structure is defined in techniques.

Microsoft Excel was used for analyzing the data of stages of hierarchical structure to design, development and formulators in. Which indicates simple and ubiquitous features of this model for all companies. While there are specialized software in this regard, but there is no need for companies to use them.

\section{Background}

A study has been done by Mandela and his colleagues in 2014. In this paper, in order to deal with bugs in FMEA and the fuzzy rules based on FMEA approaches, fuzzy numerical techniques for "failure modes and effects analysis" were introduced. Fuzzy numerical approaches are based on fuzzy modeling, and suffer providing a desired priority and also have some disadvantages such as providing a desired priority. To overcome this disadvantage, the author has expanded a new integrated model based on the concepts of fuzzy similarity with possibility theory (Mandal \& Maiti, 2013).

An article by Zheng and colleagues was done in 2012, in which safety and warning ranking in hot and humid environments of workers were evaluated.

They evaluated 3 factors and 10 sub-factors using analytic hierarchy process and fuzzy trapezoidal fuzzy numbers. Trapezoidal fuzzy numbers are approved for determination of safety indicators and evaluating safety performance of indicators and assessment results have provided a reasonable and comprehensive evaluation system (Zheng, Zhu, Tian \& Chen, 2012).

An article by Tien and colleagues has been performed to develop a systematic risk assessment framework integrated with three QFD, Failure Mode and analyzing the impacts. This study is composed of the major types of risks, causes of risks in the construction industry, as well as the risks and prevention and improvement of measurements. Also the application of fuzzy numbers, including bell-shaped trapezoidal fuzzy numbers and fuzzy numbers may be appropriate. And more research is needed to determine the appropriate fuzzy numbers (Liu, 2012).

Another study conducted in 2015 by Benjamin Dehe and David Bamford, in which they chose the management results which are functional and appropriate evaluating local health infrastructure, according to 7 criteria and 28 sub-criteria as well as the methods of analysis hierarchy process (AHP) and the evidence reasoning (ER).

The optimal operational decisions in this paper, is a combination of two methods and the combination of the MCDM are reasonable and are proposed for subsequent decisions (Dehe \& Bamford, 2015).

In 2015 Lankvmaran and colleagues, conducted a research by combining fuzzy linguistic approach and analytical network process (ANP), as well as 3 major factors and 10 sub-factors for the assessment of health and safety in the extremely hot workplaces and they declared that the high risks and issues due to safety in such environments without compromising efficiency organizations should be measured

In this study, the alarm ranking and the degree of safety in workplaces are the first and second important degrees 
(Ilangkumaran, Karthikeyan, Ramachandran, Boopathiraja \& Kirubakaran, 2015).

Santm sine and colleagues in 2016, performed a study for the prioritization of safety parameters and safety of workers in manufacturing industries, according to expert's ideas.

In this paper using analysis hierarchy process (AHP), the quality of important safety parameters and sub-parameters has been evaluated and finally, personal safety was a priority and providing personal safety equipment for workers in such workplaces has been accounted as necessary program (Satnam \& Lakhwinder, 2016).

In 2016, a study was conducted by N. Khalil and colleagues that showed that according to increasing facilities in higher level education in construction, there is increasing need for optimizing structural functions and has mentioned that current fixing actions are systematic, operational and consistent with strategies.

Risk assessment tools for construction operations due to potential risks to health and safety aspects are proposed for the evaluation of the building performance and this review is based on analysis Analytic Hierarchy Process (AHP), the opinion of experts and doctors who have been in the process, and the concepts of numerical risk has emerged as a strategic approach (Khalil, Kamaruzzaman \& Baharum, 2016).

P. Y. Emily and Joy Haas in 2016, based on the theoretical basis for measuring performance and safety management system, as well as related discussions, stated that if the value of and insight into ongoing basis be added in mining companies, it would be the best way to assess health and safety performance and finally balanced measurements and reporting approach according to classification of interventions, organization and worker's performance is recommended (Emily \& Joy, 2015).

In 2016, an article by I. Mohammadfam and colleagues was conducted with regard to occupational health and safety assessment series of "18001 standard" as a professional tool to manage and control risks as well as an integrated approach to decision-making and combination of analytical network process (ANP) and Technique for Order Preference by Similarity to Ideal Solution (TOPSIS) tool to assess, improve and promotion 18001 of standard performance level (Mohammadfam, Mojtaba, Mansour, Rostam, Yadollah \& Alireza, 2016).

In a recent article Pouresghandiani and Naji in 2016 to assess the risks quantity of work, they used (AHP) as a decision support system, to classify and organize risks and proposed a support decision making method as a system to prioritize risks according to their significance.

The output of this research has helped managers at ease, accuracy and correctness of decisions on major projects with high risks, as well as decision support systems to increase efficiency and effectiveness and reduce and control risks in the workplace is recommended (Pouresfandyani \& Najiazarpour, 2017).

Eileen Adam and colleagues in a study in 2016 (database of government) stated that the design and development phase of wind turbines to the establishment and operation of this system contains too many risks in terms of occupational health and safety, design, development, construction, transport etc.

In this study, the risks throughout the life cycle of wind turbines have been extracted and then were used to prioritize risks using AHP analysis method (Aylin, Adem \& Ali, 2016).

\section{Methods}

In this study, it was assumed that the risks of working environment and jobs have been identified thoroughly and carefully by experts in specialized fields, using appropriate techniques.

This research as a decision support system, has converted inputs such as national and international standards and laws related processes within the organization and determined by scientific methods, etc. with knowledge and experience of experts in this field, to acceptable outputs including risk prioritizing and unacceptable and sensitive risks and in this regard, proposed managers confidence which consists of reassuring the effectiveness of selection made and performed operations for reducing risks and dangerous events and diminishing wasting the resources which are generally limited.

\section{Research Pattern}

As the model shows, the current study is a part of a risk management. The proposed model is universal, it means that it can be generalized to all the industries such as building and construction and road-building industries and less risky industries such as food industry and the large industries such as oil and smaller economic units. 


\section{Risk Management}

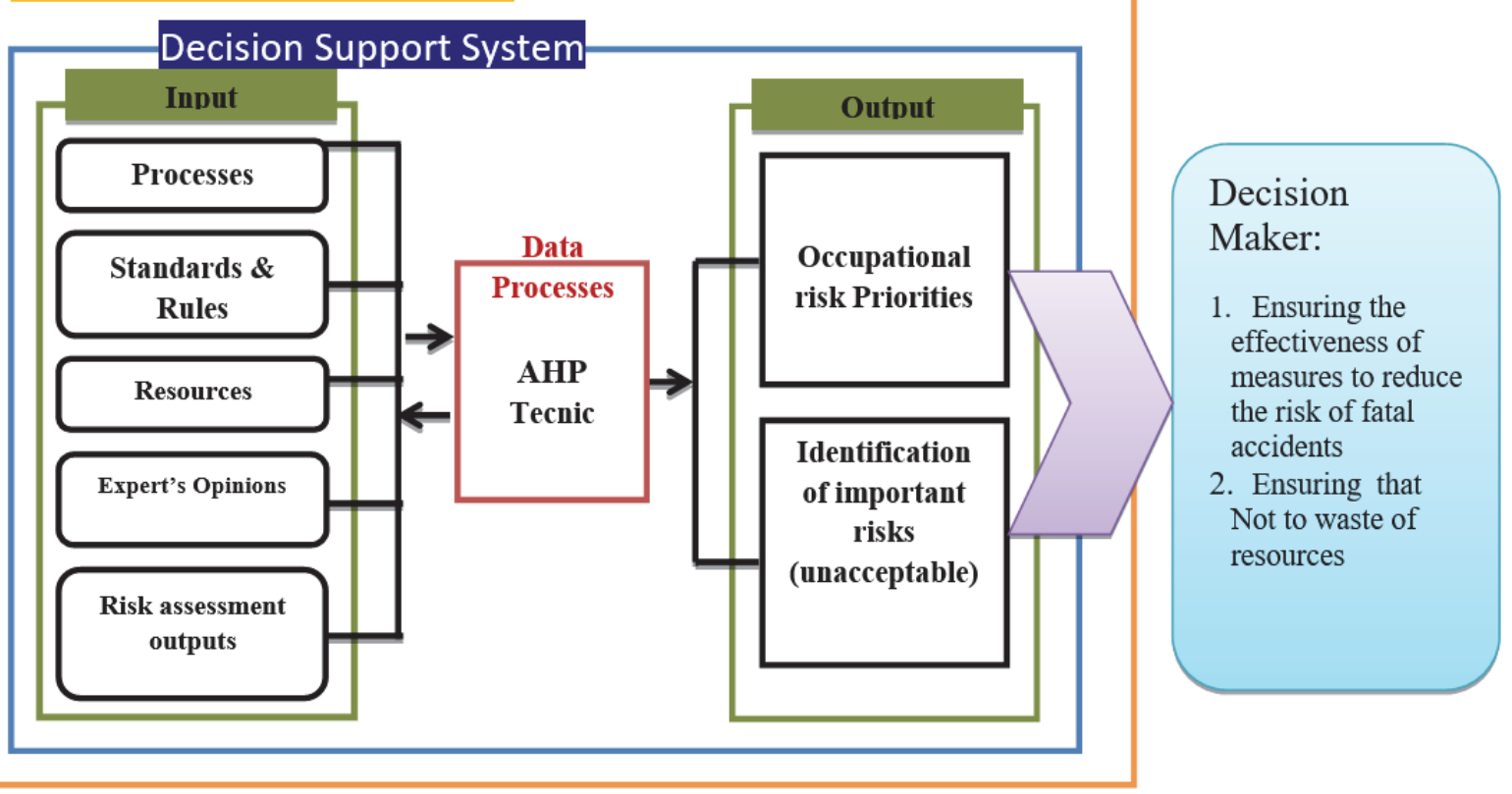

Figure 1. Research Pattern

\section{Steps}

To carry out the research we have used the opinions of experts working in the field of construction and operation of the oil industry, including directors and of HSE, and key managers of this field in the form of interviews and questionnaires.

The study assumed that a risk assessment of workplace risk assessment methods and high quality have been carried out by experts.

Analytical Hierarchy Process input data, is the output of risk assessment carried out by the experts, and this proposed model is separate from risk assessment methods.

However, in this study safety analysis activities (ASA) is used. Where RPN is calculated by the following formula:

$(1-1)$ probability $*$ severity $=$ RPN $(\mathrm{RPN})$

We used the AHP to determine the relative importance of the criteria and the options available in risk assessment, analysis of relevant data and the job is used to prioritize risks.

Questionnaires framework based on the pairwise comparison matrices hierarchical structure is defined in technique. All stages of research are relevant to the below flowchart.

RPN of each of the criteria and sub-criteria is calculated using bellow formula: 


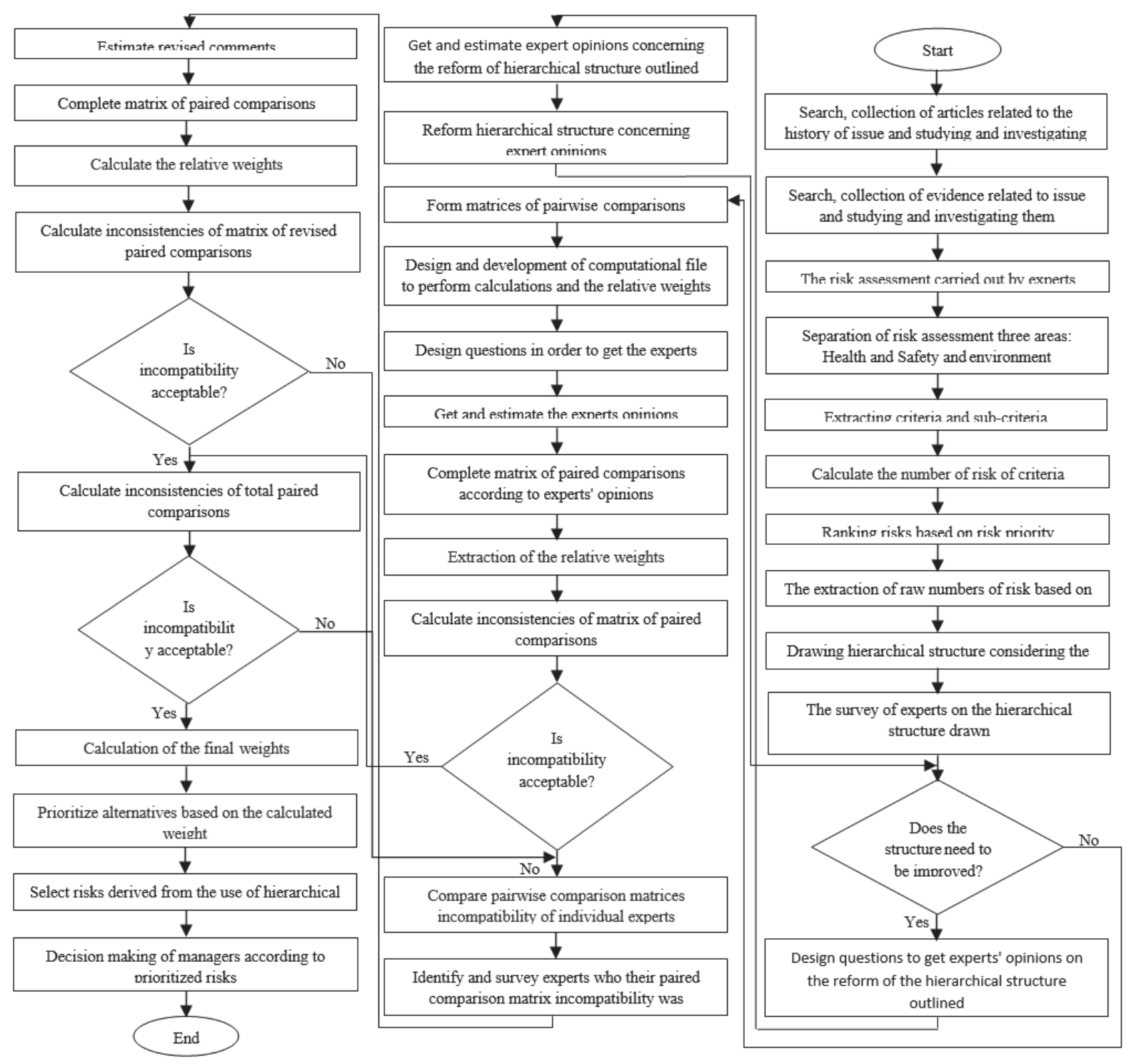

Figure 2.

In the stage of extracting high risk prioritizing numbers, researches in the fields of health, safety and environment have chosen one of the criteria with highest RPN as the sample criterion to be used in completing and drawing hierarchical structure.

At all stages, the geometric mean method was used for gathering expert opinions.

To calculate the pairwise comparison matrices incompatibility and the whole hierarchy (AHP) the following formula is used:

$$
\mathrm{CI}=\frac{\lambda_{\max }-\mathbf{m}}{\mathrm{m}-1}
$$

And to calculate random incompatibility indicators the following formula is used:

$$
\mathbf{R I}=\frac{\mathrm{CI}}{\mathbf{R}_{\mathrm{m}}}
$$

In which the number of random incompatibility is derived from bellow table: 


\begin{tabular}{|c|c|c|c|c|c|c|c|c|c|}
\hline $\mathrm{m}$ & 1 & 2 & 3 & 4 & 5 & 6 & 7 & 8 & 9 \\
\hline$R_{m}$ & 0 & 0 & 0.58 & 0.9 & 1.12 & 1.24 & 1.32 & 1.41 & 1.45 \\
\hline
\end{tabular}

To calculate average weight of incompatibility indicator, the following formula is used:

$$
\overline{\mathrm{CI}}=\mathrm{CI}(\text { Goal })+\sum_{\mathrm{j}=1}^{\mathrm{n}} \mathrm{CI}\left(\mathbf{C}_{\mathrm{J}}\right) * \mathbf{W}\left(\mathbf{C}_{\mathrm{J}}\right)
$$

Incompatibility indicator calculated from Criteria paired comparison matrix:

\section{CI (Goal)}

Incompatibility indicator calculated from alternatives paired comparison matrix in the criteria $\mathrm{j}:\left(\mathrm{C}_{\mathrm{J}}\right)$

The weight of criteria $j\left(C_{\mathrm{J}}\right)$ :

The average weight of incompatibility random number

$$
=\boldsymbol{R}_{m}(\text { Goal })+\sum_{j=1}^{n} \boldsymbol{R}_{m}\left(C_{J}\right) * W\left(C_{J}\right)
$$

The amount of criteria paired comparison of random incompatibility matrix: ${ }^{\mathbf{R}_{m}(\text { Goal })}$

$\mathbf{R}_{m}\left(\mathbf{C}_{\mathrm{J}}\right)$ : The amount of alternatives paired comparison of random incompatibility matrix in criteria $\mathrm{j}$

Random incompatibility indicator

$$
\overline{\mathbf{R}}=\frac{\overline{\mathbf{C I}}}{\overline{\mathbf{R}}}
$$

To calculate final weights, the following formula is used:

$$
w\left(A_{i}\right)=\sum_{j=1}^{n} w\left(A_{i} / C j\right) \times w(C j)
$$

In which:

\begin{tabular}{ll}
\hline The final weight of alternative I & $\mathbf{w}\left(\mathbf{A}_{\mathbf{i}}\right)$ \\
\hline The relative weight of the alternative i calculated from alternatives paired comparison & $\mathbf{w}\left(\mathbf{A}_{\mathbf{i}} / \mathbf{C j}\right)$ \\
matrix in criteria i & \\
The weight of criteria i calculated from criteria paired comparison matrix & $\mathbf{w}(\mathbf{C} \mathbf{j})$ \\
\hline
\end{tabular}

\section{Research Findings}

Researchers in accordance with the procedures specified in the flowchart, after specifying the criteria and the separation of the three areas of health, safety and environment of each other in accordance with risk assessment carried out by the relevant experts, have traced the hierarchical structure. Table of criteria, sub-criteria and alternative safety field are presented below.

The following criteria are also ways to prevent or control the causes of risks and alternative risk are:

Periodic inspection cables

The requirement to install the card and the RCD using appropriate PPE

Performing work under the hot Permit Preparing and completing daily checklist Marking the lines and cables Daily inspection by the electrical supervisor
Faulty cables and switchgear

Electric shock (stress) 
Isolating the electrical sockets

Surrounding the operation locations

Using sophisticated monitoring

wearing intact gloves

The continued presence of on-site activities guide

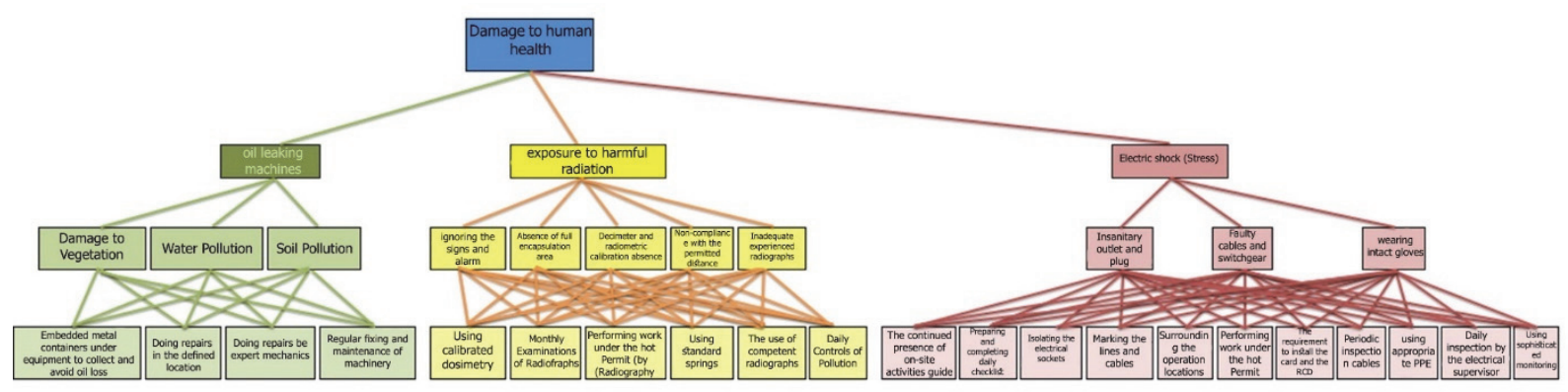

Figure 3. Hierarchical structure

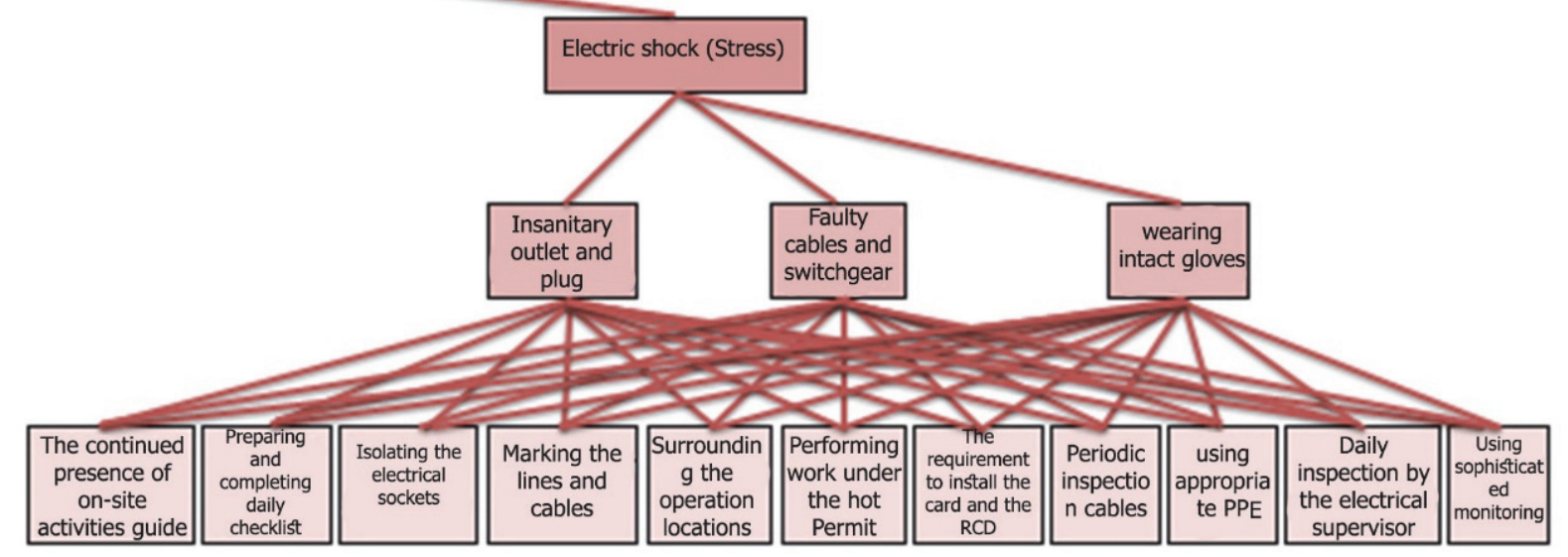

Figure 4. Hierarchical structure in safety 


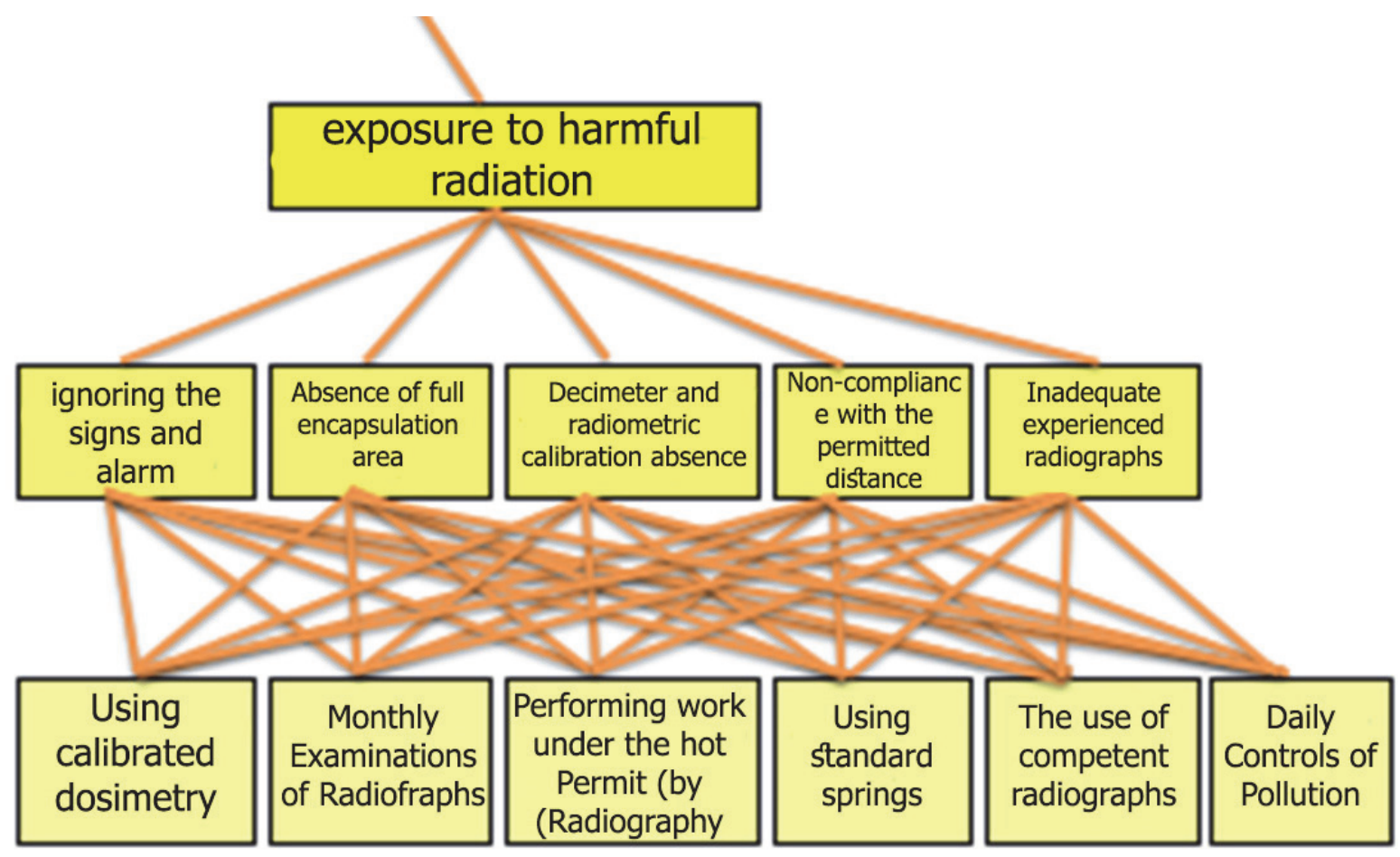

Figure 5. Hierarchical structure in health

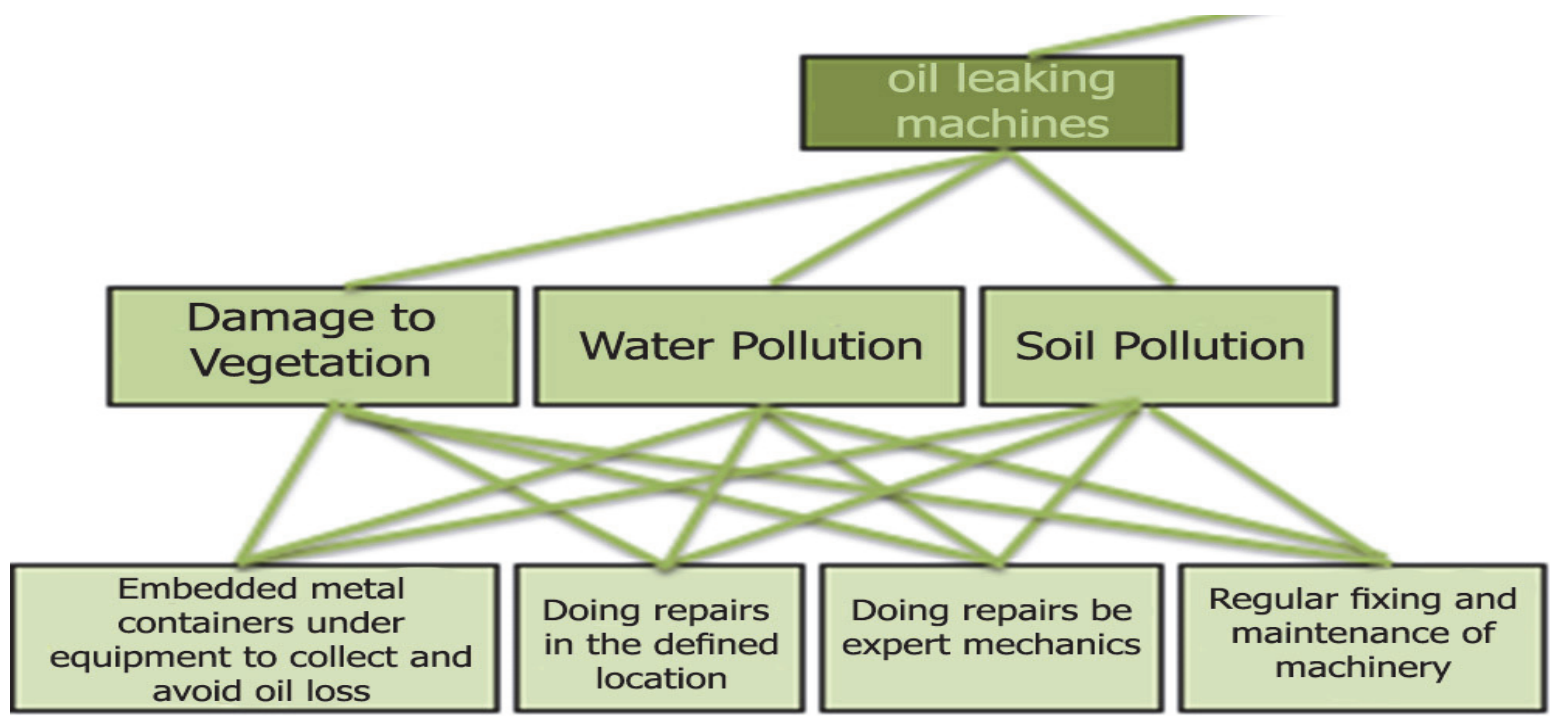

Figure 6. Hierarchical structure in environment

And according to hierarchical structure, pairwise comparison matrices, and also questions the survey of experts are designed, and the significance of each option was calculated relative to the other. Excel software was used to do it in such way that by entering the collective opinions of experts, the weight of each alternative is calculated automatically by the software. The Excel page on the field of safety standards is in accordance with the following picture: 


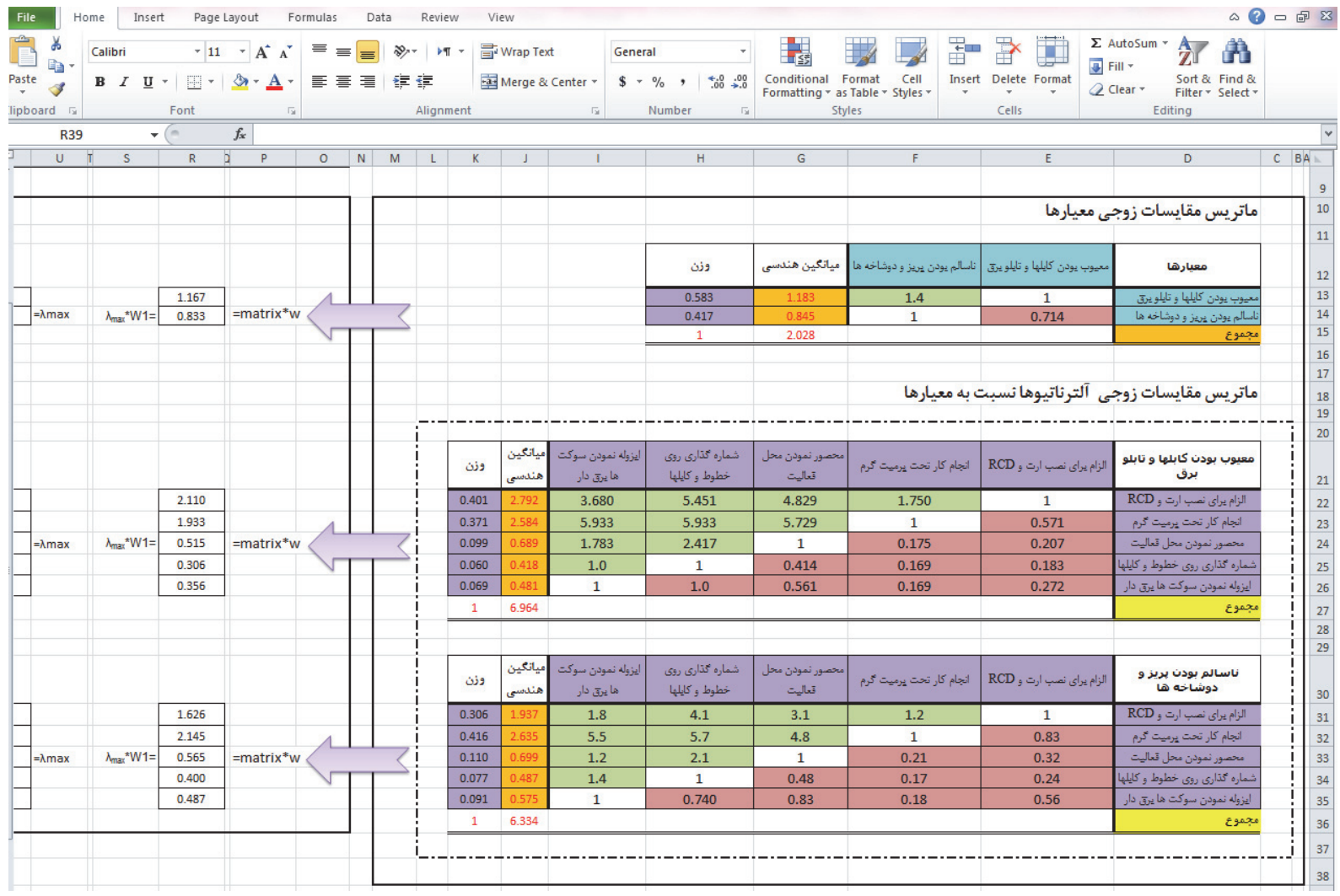

Figure 7. Calculation sheet in safety

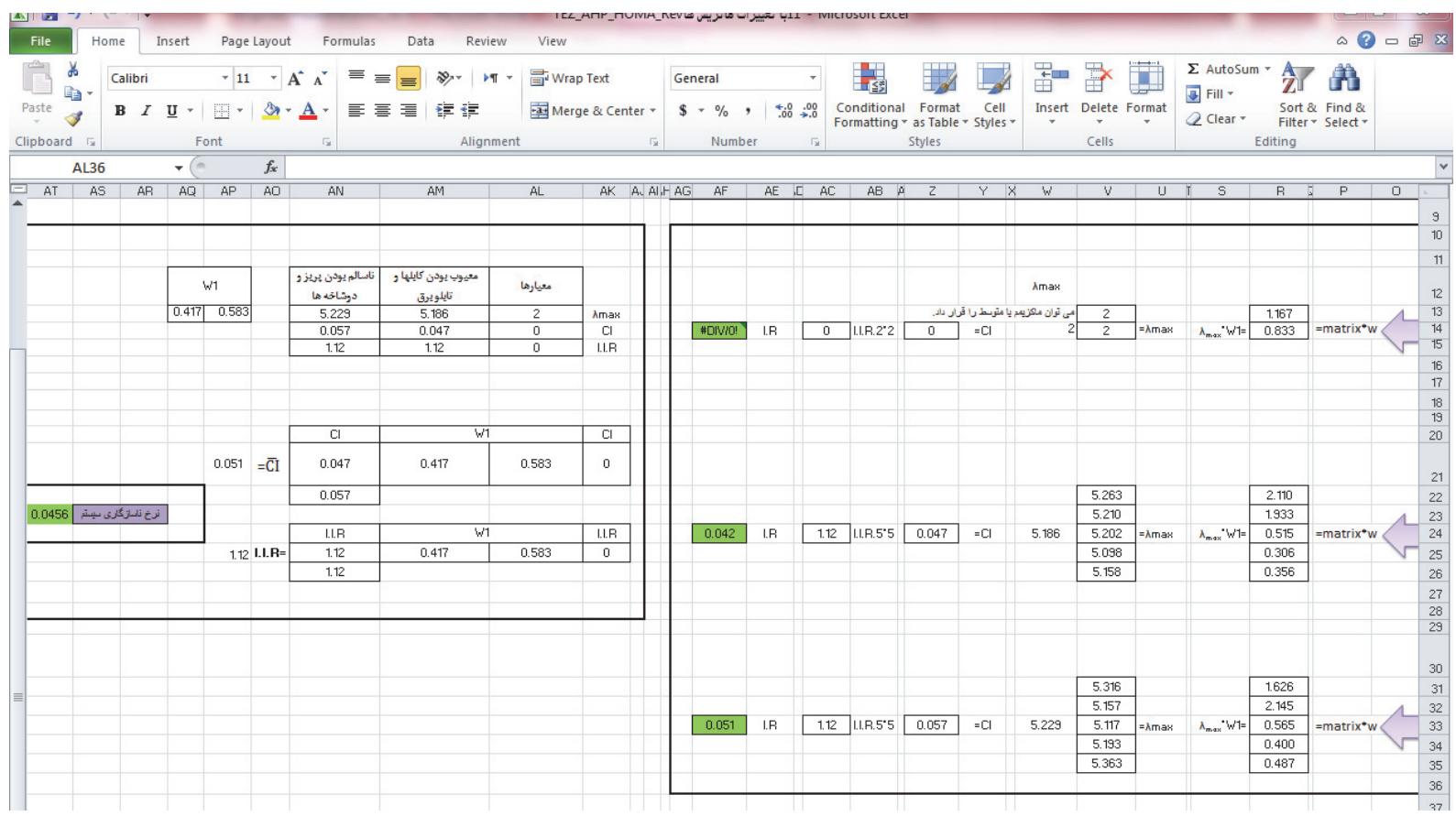

Figure 8 . Calculation sheet in safety 


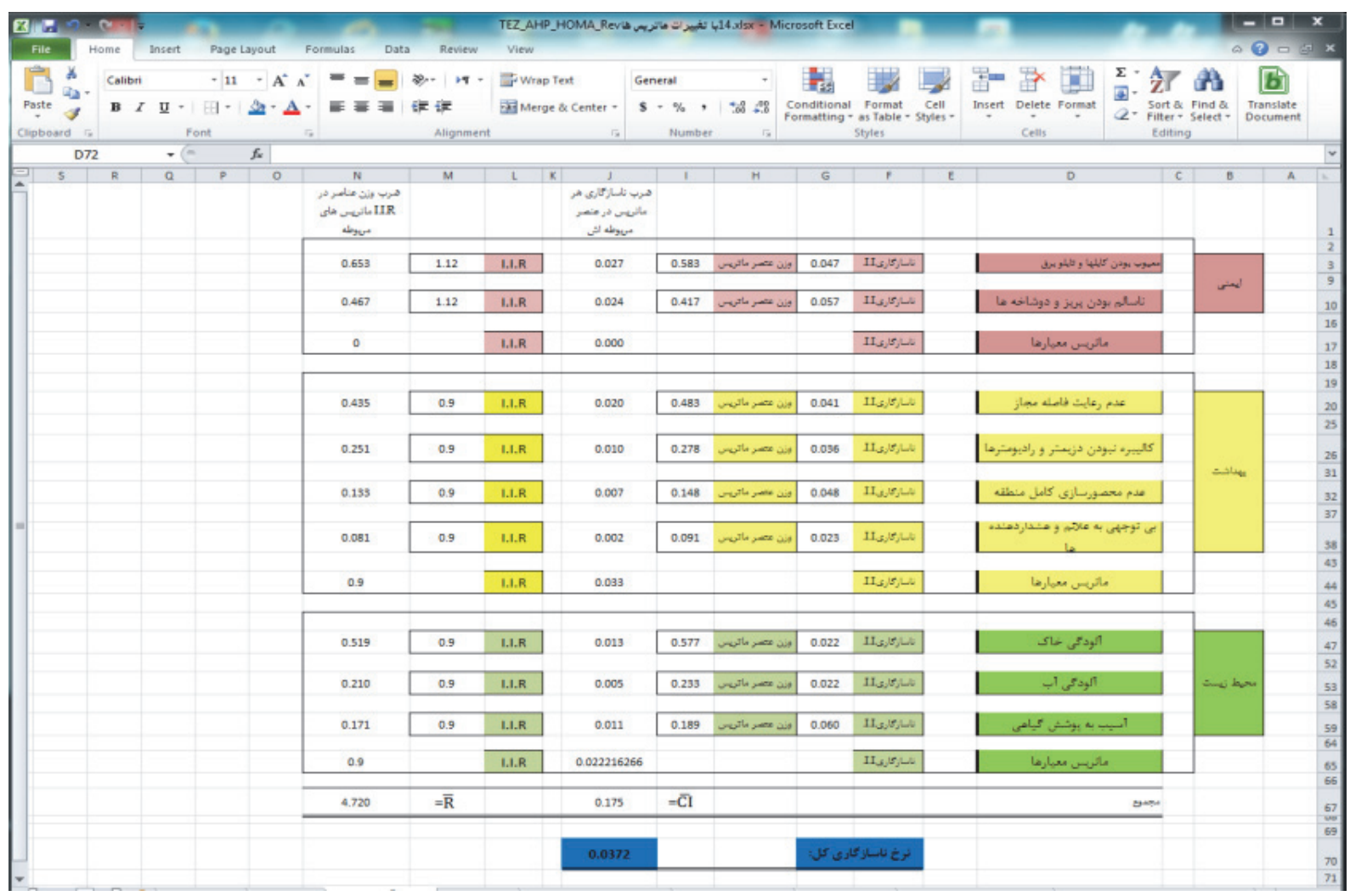

Figure 9. Calculation sheet in total incompatibility

Ultimate Ozan of each of the alternatives are obtained in the following table.

For example, in this project, the implementation of warm Permit for risky works, reduces the possibility of disaster about $31 \%$, while isolating electrical sockets reduces the risk only about $5 \%$.

Table 1. Final weight calculated for alternatives

\begin{tabular}{|c|c|c|}
\hline Final weight & Alternative & Field \\
\hline 0.31 & Performing work under the hot Permit & \multirow{5}{*}{ Safety } \\
\hline 0.26 & The requirement to install the card and the RCD & \\
\hline 0.05 & Isolating the electrical sockets & \\
\hline 0.04 & Marking the lines and cables & \\
\hline 0.00 & Surrounding the operation locations & \\
\hline 0.11 & Performing work under the hot Permit) by Radiography( & \multirow{4}{*}{ Health } \\
\hline 0.10 & Using standard springs & \\
\hline 0.03 & Monthly Examinations of Radiographs & \\
\hline 0.02 & Using calibrated dosimetry & \\
\hline 0.043 & Regular fixing and maintenance of machinery & \multirow{4}{*}{ Environmental } \\
\hline 0.010 & Doing repairs be expert mechanics & \\
\hline 0.009 & Doing repairs in the defined location & \\
\hline 0.006 & Embedded metal containers under equipment to collect and avoid oil loss & \\
\hline
\end{tabular}

Table 2. Alternatives Prioritizing

\begin{tabular}{|c|c|c|c|}
\hline Risk & $\begin{array}{lr}\text { Priorities } & \begin{array}{r}\text { Number } \\
\text { (RPN) }\end{array} \\
\end{array}$ & Alternative & Field \\
\hline 0.31 & & Performing work under the hot Permit & Safety \\
\hline 0.26 & & The requirement to install the card and the RCD & Safety \\
\hline
\end{tabular}




\begin{tabular}{|c|c|c|}
\hline 0.11 & (by Radiography) Performing work under the hot Permit & Health \\
\hline 0.10 & Using standard springs & Health \\
\hline 0.05 & Isolating the electrical sockets & Safety \\
\hline 0.04 & Marking the lines and cables & Safety \\
\hline 0.04 & Regular fixing and maintenance of machinery & Environment \\
\hline 0.03 & Monthly Examinations of Radiographs & Health \\
\hline 0.02 & Using calibrated dosimetry & Health \\
\hline 0.010 & Doing repairs be expert mechanics & Environment \\
\hline 0.009 & Doing repairs in the defined location & Environment \\
\hline 0.006 & $\begin{array}{r}\text { Embedded metal containers under equipment to collect and avoid } \\
\text { oil loss }\end{array}$ & Environment \\
\hline 0.001 & Surrounding the operation locations & Safety \\
\hline
\end{tabular}

In this step, the results of implemented prioritizing will be proposed to senior managers to be used with regard to making decision in allocating needed resources and actions in according to financial and temporal limitations.

\section{Conclusion}

With regard to the criticism of Persian literature regarding the non-use of multiple decision models in the risk assessment process and prioritizing risks and comparing it with the widespread use of non-Farsi articles and importance of exact determination of the risk of high priority for conservation and reduction of occupational risks which sometimes lead to damages, it seems that the use of these models is not only important in the risk assessment process but also it is necessary.

Table 1-3 is as a management and decision support and according to that and observing risks priorities its priorities and risks, the organization manager will go ahead with more safety and health of workers and it will result in reducing the damages specially in contractual projects.

According to it, the first activity to manage and control risks eventuate project should be implementing Licensing and Permit process for risky works which will cost for the project.

According to it, the first activity to manage and control risks eventuate project should be implemented Licensing and Permit process is risky work

0.31 g permeate performing work under a Risk Priority Number 0.31 , and the obligation to install the card and the RCD with Risk Priority Number 0.26 of the safety area is at the top of the table that shows the importance of these items and the high risk of not complying with these two.

Senior managers with respect to these items, reduce risks within the organization and reduce costs of the process due to possible accidents, and ultimately reduce the whole cycle's costs.

Also paying attention to the criteria of the environment and comply with related issues, causes reducing damage to the environment and the human health risks. So in this study, by implementing different methods of multi-criteria decision as a decision support, we can ensure that with minimal costs, the entire risks in this area will be diminished and under control.

Going through legal stages for receiving needed permits (licenses), limiting resources of development projects and more limited allocation of resources to issues of health, safety and the environment, are actions that managers should do at the beginning of the project.

Managers work with keeping security in mind, and most importantly, the pressures for its implementation by the employees, compliance with legal standards for each project,

One of the efficient measures to reduce damage to human health in development projects, is taking into account HSE items when choosing a contractor at the time of bidding by the employer and at the design stage.

\section{References}

Aylin, M. K., Adem, M. D., \& Ali, Ç. (2016). Fuzzy Prioritization Approach for Risks of Wind Turbine Life Cycle, 406-413.

Database of government. (n/a).

Decision making process in organization (written by esfandiar saadat)-library of mehr excellent training center. 
Dehe, B., \& Bamford, D. (2015). Development, test and comparison of two Multiple Criteria Decision Analysis (MCDA) models: A case of healthcare infrastructure location. Expert Syst. Appl., 42(19), 6717-6727, Nov. 2015.

Emily, P. Y., \& Joy, H. (2015). 5Exploring the state of health and safety management system performance measurement in mining organizations, 48-58.

Hao-Tien Liu, H. T. (2012). A fuzzy risk assessment approach for occupational hazards in the construction industry, 1067-1078.

Ilangkumaran, M., Karthikeyan, M., Ramachandran, T., Boopathiraja, M., \& Kirubakaran, B. (2015). Risk analysis and warning rate of hot environment for foundry industry using hybrid MCDM technique, 72, $133-135$.

Khalil, N., Kamaruzzaman, S. N., \& Baharum, M. R. (Dec. 2016). Ranking the indicators of building performance and the users' risk via Analytical Hierarchy Process (AHP): Case of Malaysia. Ecol. Indic., 71, 567-576.

Magiran, D. K. (2013). hopefull to survive environment. Energy Jounal, 6, 100.

Mandal, S., \& Maiti, J. (2013). Expert Systems with Applications Risk analysis using FMEA: Fuzzy similarity value and possibility theory based approach. Expert Syst. Appl.

Mohammadfam, I., Mojtaba, K., Mansour, M., Rostam, G., Yadollah, H., \& Alireza, S. (2016). 6Developing an integrated decision making approach to assess and promote the effectiveness of occupational health and safety, 119-133.

Pouresfandyani, H., \& Najiazarpour, S. (2017). Develop a Comprehensive System for Prioritizing Employment Risk with the Use of Multi-Criteria Decision (Using Hierarchical Techniques). Mod. Appl. Sci., 11(1), 204-208.

Satnam, S. M. K., \& Lakhwinder, P. S. (2016). 3Analytical Hierarchy Process-Based Methodology for Selection of Safety Parameters in Manufacturing Industry - Springer, 357-366.

Website (n/a). http://Modiriyat_omumi_alvani.pdf

Zheng, G. Z., Zhu, N., Tian, Z., \& Chen, Y. (2012). Application of a trapezoidal fuzzy AHP method for work safety evaluation and early warning rating of hot and humid environme, 228-239.

\section{Copyrights}

Copyright for this article is retained by the author(s), with first publication rights granted to the journal.

This is an open-access article distributed under the terms and conditions of the Creative Commons Attribution license (http://creativecommons.org/licenses/by/4.0/). 